\title{
Sayısal renk parametreleri ile toprak özellikleri arasındaki ilişkiye toprak horizonlarının etkisi*
}

\section{Effect of soil horizons on the relationship between digital color parameters and soil properties}

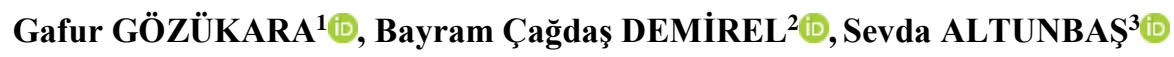 \\ ${ }^{1}$ Eskişehir Osmangazi Üniversitesi, Ziraat Fakültesi, Toprak Bilimi ve Bitki Besleme Bölümü, Eskişehir \\ ${ }^{2}$ Akdeniz Üniversitesi, Teknik Bilimler Meslek Yüksekokulu, Bitkisel ve Hayvansal Üretim Bölümü, Antalya \\ ${ }^{3}$ Akdeniz Üniversitesi, Ziraat Fakültesi, Toprak Bilimi ve Bitki Besleme Bölümü, Antalya \\ Sorumlu yazar (Corresponding author): G. Gözükara, e-posta (e-mail): ggozukara@ogu.edu.tr \\ Yazar(lar) e-posta (Author e-mail): cagdasdemirel@akdeniz.edu.tr, saltunbas@akdeniz.edu.tr
}

\section{MAKALE BILLGİSİ}

Alınış tarihi 01 Haziran 2020

Düzeltilme tarihi 03 Eylül 2020

Kabul tarihi 04 Eylül 2020

\section{Anahtar Kelimeler:}

Aksu

Alüviyal arazi

Toprak rengi

Toprağın fiziksel ve kimyasal özellikleri

\section{$\ddot{o ̈ z}$}

Toprak rengi, morfolojik, fiziksel, kimyasal ve mineralojik özellikler hakkında önemli bir veri kaynağıdır. Bu nedenle toprak bilimcileri, toprak horizon sınırlarının belirlenmesinde, renkteki farklıklardan faydalanmaktadırlar. $\mathrm{Bu}$ araştırmanın amacı $\mathrm{A}$ ve $\mathrm{C}$ horizonlarından alınan toprakların bazı fiziksel-kimyasal özellikleri ile sayısal renk parametreleri (L, a ve b) arasındaki ilişkiye etkisini belirlemektir. Alüviyal arazinin üst ve alt zonlarında bulunan 17 toprak profilinin $\mathrm{A}$ ve $\mathrm{C}$ horizonlarından toplam 91 adet toprak örneği alınmıştır. Toprak örneklerinde sayısal renk parametre değerleri (L, a ve b), tekstür, $\mathrm{pH}$, elektriksel iletkenlik, kireç, organik madde, değișebilir $\mathrm{K}, \mathrm{Na}, \mathrm{Ca}+\mathrm{Mg}$, katyon değișim kapasitesi analizleri yapılmıştır. Elde edilen sonuçlara göre, Toprağın A horizonlarında L değeri ile $\mathrm{pH}(0.77 * *)$ ve kireç $\left(0.82^{* *}\right)$ arasında, a değeri ile kum $(0.54 * *), \mathrm{Ca}+\mathrm{Mg}\left(-0.65^{* *}\right)$ ve $\mathrm{KDK}\left(-0.65^{* *}\right)$ arasında ve b değeri ile kum $\left(0.52^{* *}\right), \mathrm{Ca}+\mathrm{Mg}\left(-0.55^{* *}\right)$ ve $\mathrm{KDK}\left(-0.56^{* *}\right)$ arasında önemli korelasyon olduğu tespit edilmiştir. Toprağın $\mathrm{C}$ horizonlarında $\mathrm{L}$ değeri ile silt $\left(0.57^{* *}\right), \mathrm{pH}$ $\left(0.65^{* *}\right)$, kireç $\left(0.81^{* *}\right)$ ve $\mathrm{K}\left(-0.50^{* *}\right)$, a değeri ile kil $\left(-0.58^{* *}\right)$ ve kum $\left(0.48^{* *}\right)$ arasında ve b değeri ile kil $\left(-0.55^{* *}\right)$ ve kireç $\left(0.68^{* *}\right)$ arasında önemli korelasyon olduğu bulunmuştur. Çoklu doğrusal regresyon analiz sonuçlarına göre; A horizonlarında $\mathrm{L}$ ve a değerleri ile $\mathrm{pH}$ $\left(\mathrm{R}^{2}=0.68\right)$ ve a ve $\mathrm{b}$ değerleri ile kireç $\left(\mathrm{R}^{2}=0.73\right)$ içeriğinin, $\mathrm{C}$ horizonlarında ise $\mathrm{L}$, $\mathrm{a}$ ve $\mathrm{b}$ değerleri ile kireç içeriğinin tespit edilebileceği belirlenmiştir. Sayısal renk parametrelerinin (L, a ve b), $\mathrm{pH}$ ve kireç içeriğinin belirlenmesinde güvenilir bir şekilde kullanılabileceği ancak, bu performansın horizon farklılığından da (A ve C) etkilendiği belirlenmiştir.

\section{ARTICLE INFO}

Received 01 June 2020

Received in revised form 03 September 2020 Accepted 04 September 2020

Keywords:

Aksu

Alluvial land

Soil color

Physical and chemical properties of soil

\begin{abstract}
Soil color is an important data source about the morphological, physical, chemical and mineralogical properties of the soil. Therefore, soil scientists benefit significantly from soil color differences in determining the boundaries of soil horizons in field conditions. The aim of this research was to determine the effect of soils taken from $\mathrm{A}$ and $\mathrm{C}$ horizons on the relationship between some physical-chemical properties and digital color parameters $(\mathrm{L}$, a and b). Ninety-one soil samples were taken from the $\mathrm{A}$ and $\mathrm{C}$ horizons of 17 soil profiles in the upper and lower zones of the alluvial land. Digital color parameters ( $\mathrm{L}$, a and b), texture, $\mathrm{pH}$, electrical conductivity, lime, organic matter, exchangeable $\mathrm{K}, \mathrm{Na}, \mathrm{Ca}+\mathrm{Mg}$, cation exchange capacity (CEC) analyzes were performed in soil samples. A significant correlation was found between $\mathrm{L}$ value and $\mathrm{pH}(0.77 * *)$ and lime $(0.82 * *)$, between a value and sand $(0.54 * *)$, $\mathrm{Ca}+\mathrm{Mg}\left(-0.65^{* *}\right)$ and CEC $\left(-0.65^{* *}\right)$, and between $\mathrm{b}$ value and sand $\left(0.52^{* *}\right), \mathrm{Ca}+\mathrm{Mg}$ $\left(-0.55^{* *}\right)$ and CEC $\left(-0.56^{* *}\right)$ in the A horizons. A significant correlation was found between $\mathrm{L}$ value and silt $\left(0.57^{* *}\right), \mathrm{pH}\left(0.65^{* *}\right)$, lime $\left(0.81^{* *}\right)$ and $\mathrm{K}\left(-0.50^{* *}\right)$, between a value and clay $\left(-0.58^{* *}\right)$, sand $\left(0.48^{* *}\right)$, and between $\mathrm{b}$ and clay $\left(-0.55^{* *}\right)$, lime $\left(0.68^{* *}\right)$ in the $\mathrm{C}$ horizons. According to the results of multiple linear regression analysis; $\mathrm{pH}\left(\mathrm{R}^{2}=0.68\right)$ value can be determined with $\mathrm{L}$ and a values, and lime $\left(\mathrm{R}^{2}=0.73\right)$ content can be determined using $\mathrm{a}$ and $\mathrm{b}$ values in A horizons, and lime content can be determined using $\mathrm{L}$, a and b values in $\mathrm{C}$ horizons. It is concluded that digital color parameters can be used more reliably determining $\mathrm{pH}$ and lime content and this performance is affected by $\mathrm{A}$ and $\mathrm{C}$ horizons.
\end{abstract}




\section{Giriş}

Toprak konusunda uzmanlaşmış kişiler, pedolojik bilgi ve deneyimleri ölçüsünde, özellikle arazi koşullarında, renk, tekstür, strüktür, organik madde, kireç, nodül konkresyon, gözeneklilik ve redoksimorfik gibi gözlemlenebilir morfolojik özelliklerine dayanarak, topraklar hakkında yorum yaparlar (Gözükara ve ark. 2019; Şimşek ve ark. 2020; Gözükara ve ark. 2020). Özellikle toprak profillerinde farklı horizonların ayırt edilmesi ve sınırlarının belirlenmesinde, kullanılan-toprağın en önemli fiziksel özelliklerinden birisi toprak rengidir. Toprağın organik ve inorganik bileşenlerinin yansıma karakteristiklerine bağlı olarak, farklı toprak renkleri oluşmaktadır. Toprak özellikleri arasında en belirgin morfolojik özelliklerden birisi olan toprak rengi, toprağın mineral bileşimi (Torrent ve ark. 1980; Shen ve ark. 2006), organik madde içeriği (Schulze ve ark. 1993; Fang ve ark. 1999) tarla kapasitesi, solma noktas1, agregat stabilitesi, bitki besin elementi içeriği (Budak ve ark. 2018) ve aynı zamanda toprak nem rejimine bağlı olarak kimyasal işlemler (Ji ve ark. 2007) hakkında bilgi verebilmektedir.

Arazi ve laboratuvar koşullarında toprak renginin standart olarak belirlenmesi Munsell Renk Skalalarında kullanılan başat spektral renk (Hüe), koyuluk (Value) ve saflık (Chroma) değerlerine bağlı olarak gözleme dayalı subjektif bir yöntemle yapılmaktadır. Munsell Renk Skalaları 1941 yılında ABD'de yayınlanmış (Rice ve ark. 1941; Simonson 1993) ve günümüzde toprak rengini ölçmek için dünya çapında yaygın olarak kullanılmaktadır (Thwaites 2002). Aynı zamanda Munsell Renk Skalası Amerikan Toprak Sınıflama Sisteminde ve diğer birçok toprak sinıflama sistemlerinde, horizon özelliklerinin tanımlanmasında ve sınıflandırılmasında kullanılan önemli bir morfolojik kriterdir (Soil Survey Staff 2010; Hartemink ve Minasny 2014). Birçok araştırmacı, Munsell Renk Skalası kullanılarak yapılan toprak renk okumalarında, kişiye göre değişiklik gösterebilen subjektif eksenli olmasından dolayı, renk ifadelerinde önemli hataların olabileceğine dikkat çekmişlerdir (Post ve ark. 1993; Moritsuka ve ark. 2014). Bu hata payını azaltmak amacıyla bazı araştırmacılar toprak renginin daha hassas bir şekilde belirlenebildiği ve daha az hata payının olduğu kolorimetrik yöntemleri tercih etmişlerdir (Torrent ve Barrón 1993; Günal ve ark. 2008; Moritsuka ve ark. 2014; Budak ve ark. 2018).

Kolorimetrik yöntem olarak değerlendirilen CIELab yöntemi ilk defa 1976 yılında Comission Internationale d'Eclairage (CIE) tarafından geliştirilmiştir. Geliştirildiği günden günümüze kadar toprak bilimcilerinin artan oranda ilgisini çekmeyi başarmıştır. CIElab yönteminde renk 3 farklı skalada $\left(L^{*} a^{*} b^{*}\right)$ sayısal değerleri ile karakterize edilmektedir. $\mathrm{Bu}$ skalada " $\mathrm{L}$ " değeri rengin parlaklı̆ 1 (beyaz= 100$)$ veya koyuluğunu (siyah=0) tanımlamaktadır. " $L$ *" değerinin yüksek olması rengin daha parlak ve düşük olması ise daha koyu olduğunu ifade etmektedir. "a*" değeri kırmızı ve yeşil tonlarının tanımlanmasında kullanılmaktadır. "a*" değerinin eksi değerleri yeşil rengi ve artı değerleri ise kırmızı rengi temsil etmektedir. " $b$ *" değeri ise sarı ve mavi renkleri tanımlamakta olup, bu değer negatif olduğunda mavi, pozitif olduğunda ise sarı rengi ifade etmektedir (Barrett 2002; Fan ve ark. 2017).

Toprak renk ölçümlerinin, çok düşük maliyetlerle, arazi ve laboratuvar koşullarında rahatlıkla belirlenebilmesi, bugüne kadar birçok araştırmacının ilgisini çekmiştir. Bazı araştırmacılar renk parametresi ile toprakların morfolojik, fiziksel, kimyasal, mineralojik ve biyolojik özelliklerinin hızlı ve ekonomik olarak belirlenmesinde (Günal ve ark. 2008; Aitkenhead ve ark. 2013; Moritsuka ve ark. 2014; Baumann ve ark. 2016; Pretorius ve ark. 2017; Budak ve ark. 2018) ve hatta toprak profilinde horizon sinırlarının sayısal olarak tespit edilmesi (Zhang ve Hartemink 2019) ve toprak profillerinde litelojik kesilmelerin tahmin edilmesi (Gozukara ve ark. 2021) üzerinde $L^{*}, a^{*}$ ve $b^{*}$ değerlerinden faydalanarak araştırmalar yapmışlardır. Fakat sayısal toprak renk parametreleri ile toprak özellikleri arasındaki ilişkiyi açıklayan araştırmalarda, farklı toprak horizonu (A ve C) değişkenine bağlı olarak $L * a * b *$ değerleri ve toprak özellikleri arasındaki ilişkinin nasıl değiştiği tam olarak açıklanamamıştır.

$\mathrm{Bu}$ araştırmanın amacı, Türkiye'nin önemli ve verimli bir Alüviyal arazi üzerinde gelişen toprak profillerinin $A$ ve $C$ horizonlarından alınan toprak örneklerinin bazı fiziksel-kimyasal özellikleri ile sayısal renk parametreleri (L, a ve b) arasındaki ilişkiye etkisini belirlemektir.

\section{Materyal ve Metot}

\subsection{Materyal}

Araştırma alanı, Antalya ili Aksu ilçesi sınırları içerisinde aluviyal arazinin alt zonunu temsilen Solak Köyü sınırları ve aluviyal arazinin üst sınırlarını temsilen Köseler ve Hacıceliller Köy sınırlarından oluşmaktadır (Şekil 1). Solak Köyü arazileri araştırma kapsamında materyal olarak seçilmiştir. Bu köy aynı zamanda DSİ 13. Bölge Müdürlüğü tarafindan yürütülen, Aksu Çayı Taşkın Koruma ve Arazi Toplulaştırma Projesi kapsamında bulunmaktadır. Solak Köyü Antalya il merkezine yaklaşık $20 \mathrm{~km}$ (Solak Köyü) uzaklıkta ve 1625 ha büyüklügündedir. Köseler ve Hacıceliller Köyleri ise Antalya il merkezine yaklaşı $30 \mathrm{~km}$ uzaklıkta ve 1468 ha büyüklüğündedir. Çalışma alanı Antalya havzasının sahil kesimindeki tipik Akdeniz iklim kuşağında yer almaktadır. Bu kuşakta yazlar sıcak ve kurak, kışlar ılık ve yağışlı geçmektedir. Yıllık ortalama yağış miktarı $1068 \mathrm{~mm}$ olup, yağışlar yağmur şeklinde ve çoğunlukla ilkbahar ve kış aylarında düşmektedir. Y1ll1k ortalama sicaklık ise $18.4^{\circ} \mathrm{C}$ 'dir. Toprak taksonomisine göre (Soil Survey Staff 2014) araştırma alanının toprak nem rejimi Xeric, $50 \mathrm{~cm}$ 'deki y1llık ortalama toprak sıcaklığının $15-22^{\circ} \mathrm{C}$ arasında olması nedeniyle toprak sicaklık rejimi de Thermic olarak sınıflandırılmıştır. Araştırma alanı, günümüzde de aktif olan başta Aksu Çayı olmak üzere diğer birkaç küçük akarsuyun binlerce yıl önceki taşkınları sonucunda kuzeydeki Toros Dağlarından taşıyarak getirdiği ve çoğunluğu kireçce zengin jeolojik materyallerin birikip depolanması sonucu oluşan bir yapı arz etmektedir.

\subsection{Metot}

\subsubsection{Toprak örneklemesi ve fiziksel ve kimyasal analizler}

$\mathrm{Bu}$ çalışma kapsamında alüviyal arazinin üst zonunda Köseler ve Hacıceliller Köy sınırlarında (Şekil 1'de kırmızı poligon) bulunan 9 toprak profil ve alt zonunda bulunan Solak Köyü sınırlarında (Şekil 1'de yeşil poligon) 8 toprak profili tanımlanmıştır (Şekil 1). Tanımlanmış olan bu profillerden 41 adet $\mathrm{A}$ horizonlarından ve 50 adet $\mathrm{C}$ horizonlarından olmak üzere toplam 91 farklı horizondan bozulmuş toprak örneği alınmıştır. Toprak örnekleri hava kurusu hale getirildikten sonra 2 mm'lik elekten elenerek fiziksel ve kimyasal analizler için uygun hale getirilmiştir. Toprak örneklerinde, toprak bünyesi hidrometre yöntemi ile (Bouyoucos 1955), organik madde 
Black (1965), pH ve EC 1:2.5 toprak su karışımında (Jackson 1967), kireç $\left(\mathrm{CaCO}_{3}\right)$ Scheibler Kalsimetresi ile (Soil survey staff 1993) ve değiş̧ebilir katyonlar (DK) $1 \mathrm{~N}$ amonyum asetat yöntemine göre belirlenmiştir (Kacar 1995).

\subsubsection{Renk ölçümleri}

Fiziksel ve kimyasal analizler için gerekli ön işlemlerden geçirilmiş olan topraklar CR-400 model bir kromometre (Minolta, Osaka, Japonya) kullanılarak toprakların renk ölçümleri gerçekleştirilmiştir. 2 mm'lik elekten geçirilmiş olan toprak örnekleri plastik petri kaplarına yüzeyleri düz olacak şekilde doldurulmuştur (Şekil 2). Renk okumaları sırasında kromometre düz olan toprak yüzeyine tam temas ettirilerek toprağın $\mathrm{L}$, a ve $\mathrm{b}$ değerleri sayısallaştırılmıştır. Her toprak örneği için 5 farklı renk okuması yapılmış olup, verilerin ortalaması alınarak $\mathrm{L}^{*} \mathrm{a} * \mathrm{~b} *$ değerleri elde edilmiştir. Kromometre (Minolta, Osaka, Japonya) ölçümlerinden önce ve her 10 ölçümden sonra standart beyaz kalibrasyon tableti kullanılarak kalibrasyon işlemi gerçekleştirilmiştir.

\subsubsection{Istatistiksel analizler}

Korelasyon analizleri factominer paketi (Lê ve ark. 2008) $\mathrm{R}$ (3.4.2) istatistik programında kullanılmıştır. Çoklu regresyon analizleri JMP 13 (SAS Inc. Carry, NC) paket programı kullanılarak yapılmıştır.

\section{Bulgular ve Tartışma}

\subsection{Toprak özellikleri}

Araştırma kapsamında örneklenen toprakların fiziksel ve kimyasal özellikleri ve bu özelliklerin tespit edilmesinde kullanılan sayısal renk parametrelerinin tanımlayıcı istatistik analizleri Çizelge 1'de verilmiştir. Çalışma alanı topraklarındaki kum miktar1 \%0.52-86.32 arasında, silt miktar1 \%3.56-77.00 ve kil miktarı \%6.40-78.20 arasında değişmektedir. Toprakların kum, silt ve kil içeriklerinin oldukça geniş bir aralıkta değişim gösterdiği tespit edilmiştir. Özellikle varyasyon katsayıları (CV) incelendiğinde toprak tanecikleri arasında en fazla değişim aralığının C horizonlarındaki kum içeriğinde olduğu

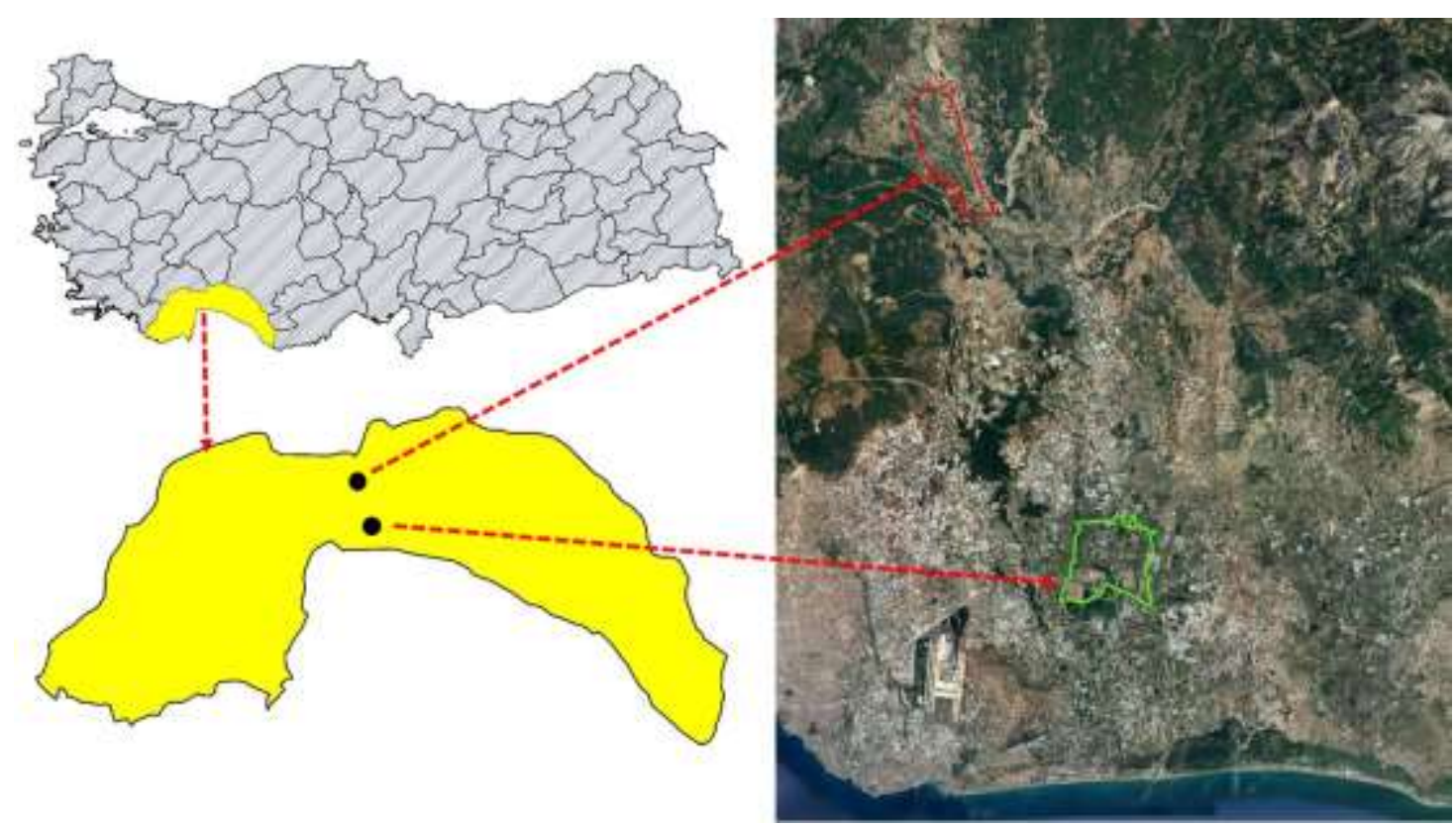

Şekil 1. Çalışma alanlarının konumları ve sınırları içerisinde yer alan alüviyal arazinin üst ve alt zonları.

Figure 1. Locations of the study areas and upper and lower zones of alluvial land located within the boundaries.

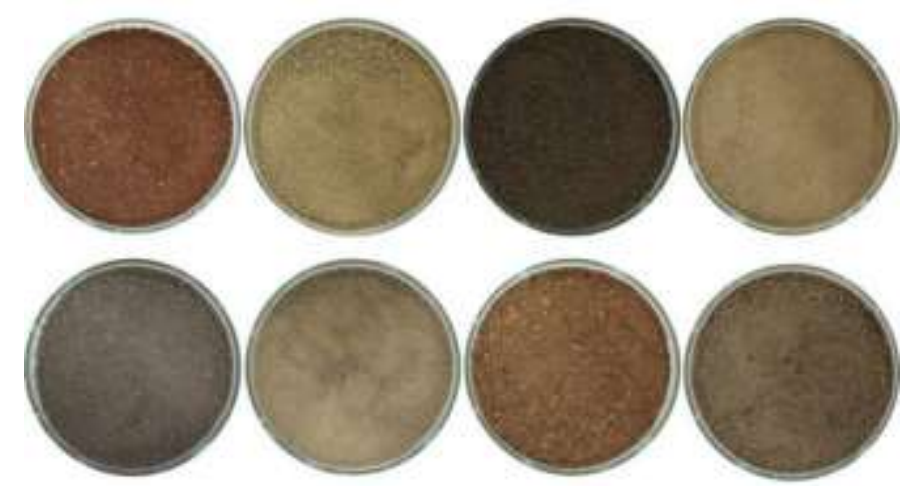

Şekil 2. Sayısal renk parametrelerinin (L, a ve b) elde edilmesinden önce cam petri kaplarındaki farklı renklerdeki toprak örneklerinden bazıları.

Figure 2. Some of the soil samples of different colors in glass petri dishes before digital color parameters (L, a and b) are obtained. 
gözlemlenmiştir. Toprak örneklerinde $\mathrm{pH}$ değerleri genel olarak hafif asidik ile hafif alkali arasında değişmekle birlikte, 6.45-7.87 arasında, EC değerinde ise toprak örneklerinde herhangi bir tuzluluk riski bulunmamakla birlikte 0.12-3.15 $\mathrm{dS} \mathrm{m}^{-1}$ arasında değişim göstermektedir. Kireç içeriğ toprakların bazılarında kireçsiz grubunda yer alırken genel itibari ile aşırı kireçli olarak \%2.98-48.61 belirlenmiştir. Organik madde (OM) miktarı \%0.60-4.91 arasında değişim göstermesine rağmen, ortalama değerlere (A horizonlarında $\% 2.26$ ve $\mathrm{C}$ horizonlarında \%1.43) göre organik madde miktarının oldukça düşük olduğu tespit edilmiştir. Toprak örneklerinde değişebilir katyonlar arasında $\mathrm{Ca}+\mathrm{Mg}$ değeri, $\mathrm{K}$ ve $\mathrm{Na}$ katyonlarına göre daha baskın olup, aynı zamanda $\mathrm{Ca}+\mathrm{Mg}$ miktarı KDK değerinde de oransal olarak diğer katyonlara göre daha fazladır. K değeri $0.16-2.14$ meq $100 \mathrm{~g}^{-1}$, Na değeri 0.01-2.01 meq $100 \mathrm{~g} \mathrm{~g}^{-1}, \mathrm{Ca}+\mathrm{Mg}$ değeri $15.66-54.50 \mathrm{meq} 100 \mathrm{~g}^{-1}$ arasında değişmektedir (Çizelge 1). Şekil 3'deki histogram grafikleri değerlendirildiğinde; genel olarak sayısal renk parametreleri (L, a ve b), kum, silt, kil, pH, EC, kireç, $\mathrm{Na}$ içerikleri $\mathrm{C}$ horizonlarında daha geniş dağılım aralığına sahipken, $\mathrm{OM}, \mathrm{K}, \mathrm{Ca}+\mathrm{Mg}$ ve $\mathrm{KDK}$ içerikleri ise $\mathrm{A}$ horizonlarında daha geniş dağılım aralığı ile daha geniş varyasyona sahip olduğu sonucuna ulaşılmıştır.

Toprak özellikleri ile sayısal renk parametreleri arasındaki pearson korelasyon katsayıları Çizelge 2'de verilmiştir. Çizelgenin sol tarafi A horizonlarındaki, sağ tarafi ise C horizonlarındaki sayısal renk parametreleri ile toprak özellikleri arasındaki pearson korelasyon katsayılarını göstermektedir.
Toprağın A horizonlarında, rengin parlaklığ $($ beyaz $=100)$ veya koyuluğu $(\operatorname{siyah}=0)$ olarak tanımlanan $\mathrm{L}$ değeri ile $\mathrm{pH}\left(0.77^{* *}\right)$ ve kireç $\left(0.82^{* *}\right)$ arasında, rengin kırmızı (pozitif değerler) ve yeşil (negatif değerler) tonlarının tanımlanmasında kullanılan a değeri ile kum $\left(0.54^{* *}\right)$, kil $\left(-0.46^{* *}\right), \mathrm{pH}\left(-0.65^{* *}\right), \mathrm{Ca}+\mathrm{Mg}$ $(-0.65 * *)$ ve $\operatorname{KDK}\left(-0.65^{* *}\right)$ arasinda ve rengin sar1 (pozitif değerler) ve mavi (negatif değerler) tonlarının tanımlanmasında kullanılan b değeri ile kum $\left(0.52^{* *}\right)$, kil $\left(0.68^{* *}\right), \mathrm{Ca}+\mathrm{Mg}$ $\left(-0.55^{* *}\right)$ ve $\mathrm{KDK}\left(-0.56^{* *}\right)$ arasında önemli korelasyon olduğu tespit edilmiştir. Toprağın $\mathrm{C}$ horizonlarında $\mathrm{L}$ değeri ile silt $\left(0.57^{* *}\right), \mathrm{pH}\left(0.65^{* *}\right)$, kireç $\left(0.81^{* *}\right)$ ve $\mathrm{K}\left(-0.50^{* *}\right)$ arasında, a değeri ile kil $\left(-0.55^{* *}\right)$ ve kireç $\left(0.68^{* *}\right)$ ve $\mathrm{b}$ değeri ile kil $\left(-0.55^{* *}\right)$ kireç $\left(0.68^{* *}\right), \mathrm{Ca}+\mathrm{Mg}\left(-0.55^{* *}\right)$ ve $\mathrm{KDK}\left(-0.56^{* *}\right)$ arasında önemli korelasyon olduğu tespit edilmiştir. Genel olarak sayisal renk parametreleri (L, a ve b) ile toprak özelliklerinden $\mathrm{pH}$, kireç, kum, kil, $\mathrm{Ca}+\mathrm{Mg}$ ve $\mathrm{KDK}$ değerleri arasında A horizonlarında daha yüksek korelasyon $(\mathrm{p}>0.01)$ tespit edilirken, $\mathrm{C}$ horizonlarında ise sayısal renk parametreleri (L, a ve b) ile toprak özelliklerinden silt ve $\mathrm{K}$ arasında daha yüksek korelasyon $(\mathrm{p}>0.01)$ tespit edilmiştir. $\mathrm{A}$ ve $\mathrm{C}$ horizonlarındaki özellikle kireç miktarının fazla ve organik madde miktarının ve kil miktarının az olması toprağın daha açık renkli olmasına katkı sağlamaktadır. Tam tersi koşullarda ise toprakların koyu renkli olmasına katkı sağlamaktadır. Bunun sonucunda rengin parlaklığ 1 (beyaz $=100$ ) veya koyuluğunu $($ siyah $=0)$ temsil eden $\mathrm{L}$ değeri ile kireç miktarı arasında pozitif, organik madde ve kil miktarı ile negatif korelasyon oluşmaktadır. Aitkenhead ve ark. (2013) toprak tanecik

Çizelge 1. A ve $\mathrm{C}$ horizonlarındaki toprak özelliklerine ait tanımlayıcı istatistikler.

Table 1. Descriptive statistics for soil properties in $\mathrm{A}$ and $\mathrm{C}$ horizons.

\begin{tabular}{|c|c|c|c|c|c|c|c|c|c|}
\hline Toprak Özelliği & Birim & Horizon & Min. & 1st.Qu & Med. & Ort. & 3rd Qu. & Max. & $\mathrm{CV}$ \\
\hline \multirow{2}{*}{$\mathrm{L}$} & & $\mathrm{A}$ & 34.66 & 50.98 & 53.61 & 52.42 & 55.49 & 59.35 & 10.27 \\
\hline & & $\mathrm{C}$ & 38.28 & 50.46 & 55.47 & 54.67 & 58.83 & 65.38 & 10.20 \\
\hline \multirow[b]{2}{*}{$\mathrm{a}$} & & A & 3.12 & 5.94 & 6.64 & 6.67 & 7.31 & 13.17 & 27.74 \\
\hline & & $\mathrm{C}$ & 4.02 & 5.99 & 6.99 & 7.01 & 7.93 & 10.89 & 20.45 \\
\hline \multirow{2}{*}{$\mathrm{b}$} & & A & 6.87 & 13.72 & 15.24 & 14.32 & 15.89 & 19.00 & 18.47 \\
\hline & & $\mathrm{C}$ & 10.42 & 14.26 & 16.95 & 16.12 & 17.99 & 21.88 & 17.38 \\
\hline \multirow{2}{*}{ Kum } & \multirow{2}{*}{$\%$} & A & 0.52 & 9.02 & 21.68 & 23.78 & 36.96 & 64.96 & 71.04 \\
\hline & & $\mathrm{C}$ & 0.88 & 9.36 & 25.96 & 28.15 & 39.13 & 86.32 & 78.47 \\
\hline \multirow{2}{*}{ Silt } & \multirow{2}{*}{$\%$} & A & 11.28 & 33.28 & 39.92 & 39.21 & 46.28 & 57.28 & 25.81 \\
\hline & & $\mathrm{C}$ & 3.56 & 27.78 & 35.21 & 36.09 & 45.81 & 77.00 & 40.81 \\
\hline \multirow{2}{*}{ Kil } & \multirow{2}{*}{$\%$} & A & 12.04 & 26.90 & 34.56 & 37.01 & 45.38 & 62.20 & 35.92 \\
\hline & & $\mathrm{C}$ & 6.40 & 24.35 & 33.58 & 35.75 & 43.84 & 78.20 & 46.95 \\
\hline \multirow{2}{*}{$\mathrm{pH}$} & \multirow{4}{*}{$\mathrm{dS} \mathrm{m}^{-1}$} & A & 6.45 & 7.35 & 7.41 & 7.39 & 7.50 & 7.75 & 3.38 \\
\hline & & $\mathrm{C}$ & 7.12 & 7.42 & 7.50 & 7.52 & 7.63 & 7.87 & 1.97 \\
\hline \multirow{2}{*}{$\mathrm{EC}$} & & A & 122.9 & 213.3 & 281.6 & 483.4 & 385.0 & 3140 & 126.22 \\
\hline & & $\mathrm{C}$ & 156.0 & 184 & 260.0 & 544.0 & 339.0 & 3152 & 145.55 \\
\hline \multirow{2}{*}{ Kireç } & \multirow{2}{*}{$\%$} & A & 2.98 & 23.81 & 30.50 & 28.44 & 32.95 & 42.42 & 31.07 \\
\hline & & $\mathrm{C}$ & 5.02 & 24.44 & 32.13 & 30.93 & 37.09 & 48.61 & 32.35 \\
\hline \multirow{2}{*}{ OM } & \multirow{2}{*}{$\%$} & A & 1.04 & 1.79 & 2.23 & 2.26 & 2.68 & 4.91 & 32.94 \\
\hline & & $\mathrm{C}$ & 0.60 & 1.00 & 1.34 & 1.43 & 1.64 & 2.83 & 39.56 \\
\hline \multirow{2}{*}{ K } & \multirow{2}{*}{ meq $100 \mathrm{~g}^{-1}$} & A & 0.34 & 0.60 & 0.71 & 0.83 & 0.97 & 2.14 & 48.41 \\
\hline & & $\mathrm{C}$ & 0.16 & 0.41 & 0.50 & 0.55 & 0.64 & 1.30 & 38.20 \\
\hline \multirow[b]{2}{*}{$\mathrm{Na}$} & \multirow{2}{*}{ meq $100 \mathrm{~g}^{-1}$} & A & 0.01 & 0.10 & 0.19 & 0.23 & 0.35 & 0.80 & 81.94 \\
\hline & & $\mathrm{C}$ & 0.01 & 0.10 & 0.23 & 0.39 & 0.50 & 2.01 & 117.82 \\
\hline \multirow{2}{*}{$\mathrm{Ca}+\mathrm{Mg}$} & \multirow{2}{*}{ meq $100 \mathrm{~g}^{-1}$} & A & 15.66 & 28.58 & 31.38 & 33.88 & 38.84 & 52.49 & 25.79 \\
\hline & & $\mathrm{C}$ & 20.81 & 29.81 & 32.51 & 34.21 & 38.44 & 54.50 & 22.26 \\
\hline \multirow{2}{*}{ KDK } & \multirow{2}{*}{ meq $100 \mathrm{~g}^{-1}$} & A & 16.72 & 30.01 & 33.20 & 34.94 & 40.25 & 53.49 & 25.13 \\
\hline & & $\mathrm{C}$ & 22.17 & 30.84 & 33.25 & 35.15 & 39.34 & 55.28 & 21.63 \\
\hline
\end{tabular}

**Min.: Minimum, Med.: Medyan, Ort.: Ortalama, Max.: Maksimum, CV: Varyans katsayısı. 

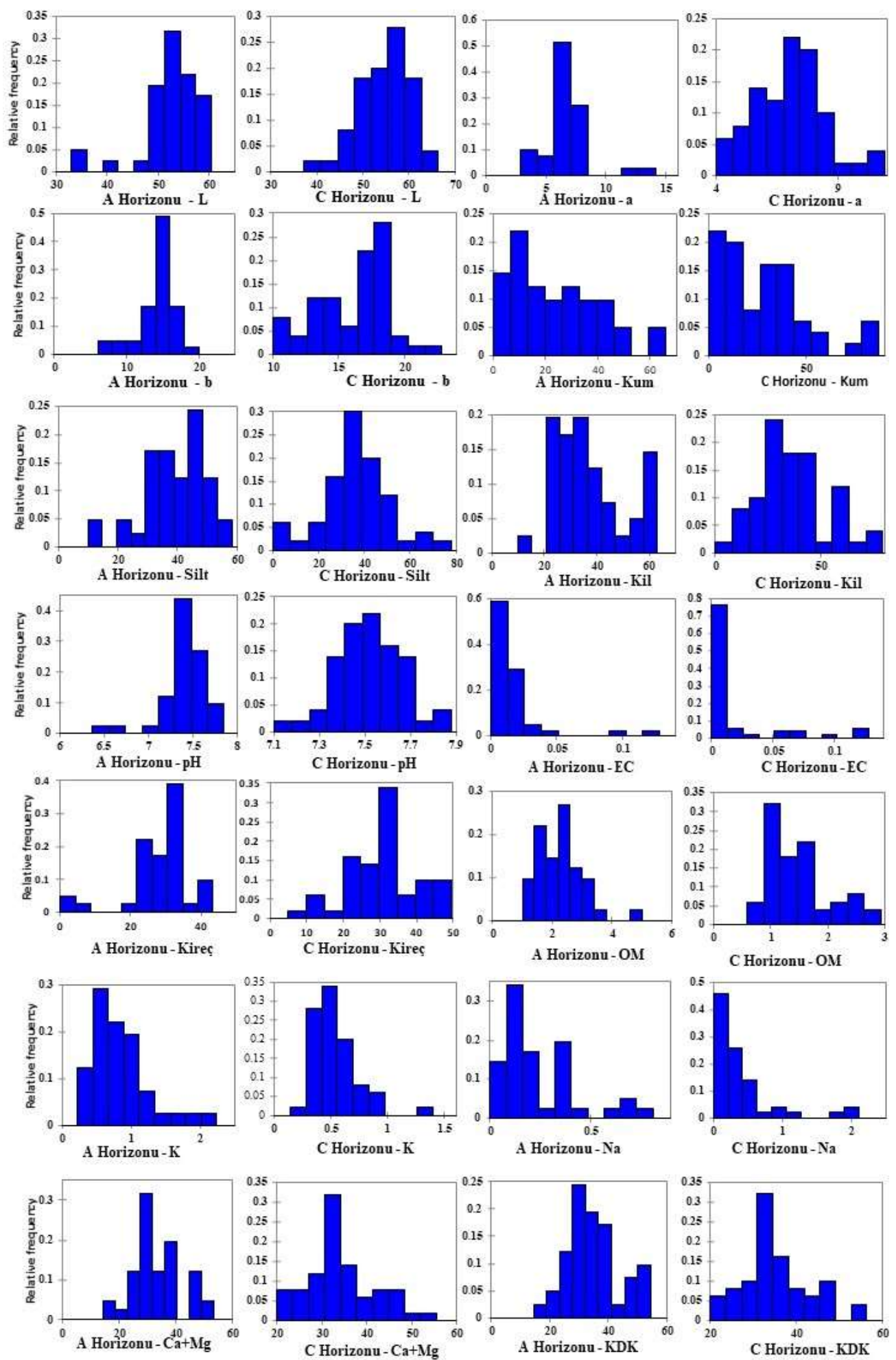

Şekil 3. Sayısal renk parametreleri ve toprak özelliklerinin A ve C horizonlarına göre histogram grafikleri.

Figure 3. Histogram graphics of digital color parameters and soil properties according to $\mathrm{A}$ and $\mathrm{C}$ horizons.

boyutunun (kum, silt ve kil) oransal dağılımının toprak rengi üzerine önemli etkisi olduğunu belirtmiştir. Araştırmacının bu bulgusu A ve C horizonlarındaki özellikle a değerinin kum ile negatif, silt ve kil ile pozitif korelasyon göstermesini açıklamaktadır.
A ve $C$ horizonlarındaki toprak özellikleri ile sayısal renk parametreleri arasındaki korelasyon katsayılarındaki farklılıkların toprak oluşum faktörleri ektisi altında pedogenetiksel olarak horizonlardaki değişim, dönüşüm, yıkanma, birikme ve ayrışma düzeyindeki farklılıklardan kaynaklandığg düşünülmektedir. 
Çizelge 2. A ve C horizonlarında sayısal renk parametreleri ve toprak özellikleri arasındaki pearson korelasyon katsayıları.

Table 2. Pearson correlation coefficients between digital color parameters and soil properties in $\mathrm{A}$ and $\mathrm{C}$ horizons.

\begin{tabular}{|c|c|c|c|c|c|c|c|c|c|c|c|c|c|c|}
\hline $\begin{array}{l}\text { Toprak } \\
\text { Özelliği }\end{array}$ & $\mathbf{L}$ & $\mathbf{a}$ & b & Kum & Silt & Kil & pH & EC & Kireç & OM & $\mathbf{K}$ & $\mathbf{N a}$ & $\mathrm{Ca}+\mathrm{Mg}$ & KDK \\
\hline $\mathbf{L}$ & 1 & -0.09 & $0.54^{* *}$ & $-0.36^{* *}$ & $0.57^{* *}$ & -0.02 & $0.65^{* *}$ & $0.44^{* *}$ & $0.81^{* *}$ & -0.26 & $-0.50^{* *}$ & $0.29^{*}$ & -0.03 & -0.03 \\
\hline $\mathbf{a}$ & $-0.50^{* *}$ & 1 & $0.64^{* *}$ & $0.48^{* *}$ & -0.06 & $-0.58^{* *}$ & 0.04 & -0.07 & 0.04 & -0.01 & -0.19 & -0.20 & -0.26 & $-0.28^{*}$ \\
\hline b & 0.18 & $0.72^{* *}$ & 1 & 0.24 & 0.26 & $-0.55^{* *}$ & $0.37^{\text {** }}$ & $0.40^{* *}$ & $0.68^{* *}$ & -0.23 & $-0.46^{* * *}$ & 0.25 & $-0.33^{*}$ & $-0.33^{*}$ \\
\hline Kum & -0.16 & $0.54^{* *}$ & $0.52^{* *}$ & 1 & $-0.65^{* *}$ & $-0.75^{* *}$ & $-0.28^{*}$ & -0.03 & 0.01 & -0.09 & -0.15 & -0.11 & $-0.57^{* *}$ & $-0.59^{* *}$ \\
\hline Silt & $0.35^{*}$ & -0.29 & 0.02 & $-0.62^{* *}$ & 1 & -0.02 & 0.18 & $0.46^{* *}$ & $0.35^{*}$ & 0.08 & 0.04 & 0.06 & $0.44^{* *}$ & $0.44^{* *}$ \\
\hline Kil & -0.06 & $-0.46^{* *}$ & $-0.68^{* *}$ & $-0.80^{* *}$ & 0.02 & 1 & 0.22 & $-0.37^{* *}$ & $-0.31^{*}$ & 0.05 & 0.17 & 0.09 & $0.37^{* *}$ & $0.38^{* *}$ \\
\hline pH & $0.77^{* *}$ & $-0.65^{* *}$ & -0.13 & $-0.39^{*}$ & $0.41^{* *}$ & 0.18 & 1 & -0.04 & $0.49^{* *}$ & $-0.28^{*}$ & $-0.55^{* *}$ & $0.32^{*}$ & -0.28 & -0.28 \\
\hline EC & -0.01 & 0.05 & 0.13 & 0.13 & -0.02 & -0.15 & 0.04 & 1 & $0.64^{* *}$ & -0.24 & -0.06 & $0.51^{* *}$ & 0.08 & 0.11 \\
\hline Kireç & $0.82^{* * *}$ & $-0.38^{*}$ & 0.26 & 0.08 & $0.32^{*}$ & $-0.34^{*}$ & $0.55^{* *}$ & -0.01 & 1 & $-0.35^{*}$ & $-0.54^{* *}$ & $0.51^{* *}$ & $-0.36^{* *}$ & $-0.35^{*}$ \\
\hline OM & -0.09 & -0.26 & $-0.36^{*}$ & -0.04 & -0.02 & 0.06 & -0.04 & 0.12 & 0.01 & 1 & 0.28 & -0.17 & 0.21 & 0.20 \\
\hline $\mathbf{K}$ & $-0.36^{*}$ & 0.04 & -0.10 & -0.16 & 0.16 & 0.08 & $-0.37^{*}$ & -0.05 & -0.20 & 0.23 & 1 & -0.26 & $0.40^{* *}$ & $0.42^{* *}$ \\
\hline $\mathrm{Na}$ & $0.38^{*}$ & -0.22 & -0.04 & -0.11 & 0.02 & 0.13 & 0.17 & 0.11 & $0.36^{*}$ & 0.23 & -0.26 & 1 & -0.24 & -0.18 \\
\hline $\mathrm{Ca}+\mathrm{Mg}$ & $0.32^{*}$ & $-0.65^{* * *}$ & $-0.55^{* *}$ & $-0.44^{* *}$ & -0.01 & $0.57^{* *}$ & $0.36^{*}$ & 0.03 & 0.07 & 0.22 & 0.02 & 0.13 & 1 & $0.99^{* *}$ \\
\hline KDK & $0.31^{*}$ & $-0.65^{* *}$ & $-0.56^{* *}$ & $-0.45^{* *}$ & -0.01 & $0.57^{* *}$ & $0.35^{*}$ & 0.03 & 0.07 & 0.23 & 0.06 & 0.14 & $0.99^{* *}$ & 1 \\
\hline
\end{tabular}

Çalışma alanı topraklarının sayısal renk parametreleri ile toprakların A ve $\mathrm{C}$ horizonlarındaki toprak özellikleri arasındaki regresyon analizi sonucunda elde edilen $\mathrm{R}^{2}$ değerleri Şekil 4'de verilmiştir. A ve $C$ horizonlarında $\mathrm{R}^{2}>0.5$ olan $\mathrm{pH}$ ve kireç içerikleri arasındaki regresyon analizine ait değerler ise Şekil 5'te verilmiştir. Aitkenhead ve ark. (2013) toprak özellikleri ile sayısal renk parametreleri arasında regresyon analizi ile elde edilen $\mathrm{R}^{2}$ değerinin $\geq 0.5$ olduğu koşullarda, ilgili sayısal parametrelerin toprak özelliklerini belirlemede iyi ve yeterli olabileceğini ifade etmişlerdir. Çalışma alanı toprakları ile sayısal renk parametreleri arasındaki regresyon analiz sonuçları incelendiğinde, toprak taneciklerinin (kum, silt ve kil) sayısal renk parametreleri ile belirlenmesinde $a$ ve $b$ değerlerinin $L$ değerine göre performansının daha yüksek olduğu tespit edilmiştir. Aitkenhead ve ark. (2013) ve Budak ve ark. (2018) toprak taneciklerinin belirlenmesinde benzer sonuçları rapor etmişlerdir. A horizonlarında $\mathrm{L}$ değeri ile $\mathrm{pH}\left(\mathrm{R}^{2}=0.59\right)$ ve kireç $\left(R^{2}=0.67\right)$ arasında ve $C$ horizonlarında $L$ değeri ile kireç $\left(\mathrm{R}^{2}=0.66\right)$ içeriği arasındaki ilişkinin yüksek doğrulukta belirlenebileceği tespit edilmiştir (Şekil 4). Budak ve ark. (2018) L değeri kullanarak kireç içeriğinin belirlenmesinde araştırma sonuçlarımıza yakın yüksek doğrulukla $\left(\mathrm{R}^{2}=0.59\right)$ belirlenebileceğini belirtmişlerdir. Fakat, araştırmacılar sayısal renk parametreleri ile $\mathrm{pH}$ değeri arasındaki regresyon katsayısını çalışmamızda elde ettiğimiz yüksek doğruluğa yakın doğrulukta elde edememişlerdir. $\mathrm{Bu}$ uyumsuzluğun ana materyalin karakteristik özelliklerinden kaynaklanmış olabileceği düşünülmektedir. Rengin parlaklığı (beyaz= 100) veya koyuluğu (siyah 0 ) olarak tanımlanan L değeri ile araştırma alanı topraklarının hem A horizonlarında hem de $\mathrm{C}$ horizonlarında OM beklenenin aksine yüksek doğruluk ile tespit edilememiştir. Yüksek doğruluk tespit edilememesinde toprak örneklerimizdeki OM'nin henüz toprağın rengini koyulaştıracak miktarda ve düzeyde ayrışmaya sahip olmaması ve aynı zamanda kökeninin açık renkli çok küçük kılcal kök parçaları olmasından dolayı L değeri ile OM miktarı arasında düşük doğruluk performansına neden olduğu sonucuna varılmıştır. Aynı zamanda Vodyanitskii ve Kirillova (2016) ve Budak ve ark. (2018) yaptıkları araştırma kapsamında bulgularımıza paralel olarak OM'nin L sayısal renk parametresi ile yüksek bir doğrulukla tespit edilemediğini rapor etmişlerdir. Vodyanitskii ve Kirillova (2016) teorik olarak parlaklık değeri ile organik madde içeriğinin belirlenmesinin mümkün olabileceğini bildirilirken, pratikte organik madde miktarı ile parlaklık değeri arasındaki zayıf ilişkinin organik madde içeriğinin belirlenmesine izin vermediğini rapor etmiştir. Budak ve ark. (2018) ise araştırma topraklarındaki organik madde miktarının düşük olması ile birlikte L değeri ile organik madde arasındaki ilişkinin zayıfladığını belirtmişlerdir. Budak ve Günal (2016) ve Barret (2002) topraktaki beyaz rengin ve parlaklığın kaynaklarından birisi olan tuzluluk (EC) değerinin yüksek olduğu koşullar altında L değeri ile pozitif korelasyon içinde olduğunu ifade etmiş̧lerdir. Araştırma bulgularımızda C horizonlarının EC değerlerinin göreceli olarak A horizonlarına göre daha fazla olması, L ve EC değerleri arasındaki korelasyon katsayısının $\mathrm{C}$ horizonlarında daha yüksek oranda ilişkili olduğu sonucunu göstermektedir. Fakat özellikle C horizonlarındaki nispeten yüksek pearson korelasyon katsayısına rağmen, sayısal renk parametreleri ile EC değerinin belirlenememiş olması ve araştırma topraklarında EC değerlerinin oldukça düşük olması (A ve C horizonlarında Min $=\% 0.01 \mathrm{Max}=\% 0.12$ ) beklenen etkinin ortaya çıkmasını engellediği yönünde bir düşünce geliştirmemize sebep olmuştur. Budak ve ark. (2018)'nın EC ve $\mathrm{L}$ değeri arasındaki bulguları, yaptığımız araştırma sonucumuz ile benzerlik göstermektedir.

Sayısal renk parametreleri ile toprak özelliklerinin belirlenmesinde başarı performansını arttırmak amacıyla yapılan çoklu doğrusal regresyon analiz sonuçları Çizelge 3'de gösterilmiştir. Regresyon analiz sonuçlarına göre L sayısal renk parametresi ile A horizonlarındaki $\mathrm{pH}$ değeri $\mathrm{R}^{2}=0.59$ ile tespit edilebilirken, çoklu regresyon analizi ile $\mathrm{L}$ ve a sayısal renk parametrelerinin birlikte kullanılması ile birlikte yükselerek $\mathrm{R}^{2}=0.68$ değerine ulaşmaktadır. $\mathrm{C}$ horizonlarında ise horizonlarındaki kireç miktarı $\mathrm{R}^{2}=0.66$ ile tespit edilebilirken, çoklu regresyon analizi ile $\mathrm{L}$, a ve $\mathrm{b}$ sayısal renk parametrelerinin birlikte kullanılması ile yükselerek $R^{2}=0.79$ değerine ulaşmaktadır. Sonuç olarak çoklu regresyon analizleri ile birlikte A horizonlarında $\mathrm{pH}$ ve kireç içerikleri ile $\mathrm{C}$ horizonlarında kireç içeriklerinin yüksek doğrulukla belirlenme oranlarında artışlar tespit edilmiştir (Çizelge 3). 

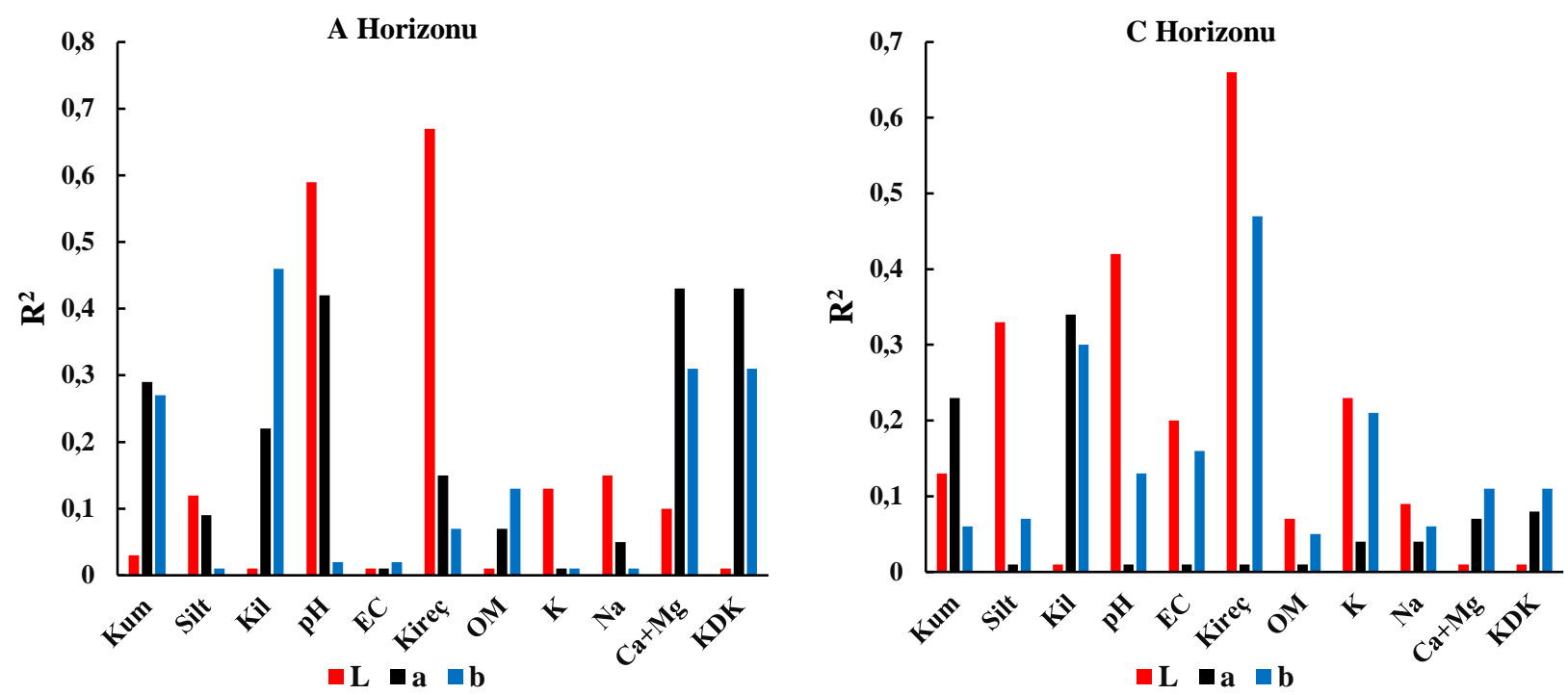

Şekil 4. Sayısal renk parametreleri ile toprak özellikleri arasındaki regresyon analiz değerleri.

Figure 4. Regression analysis values between digital color parameters and soil properties.
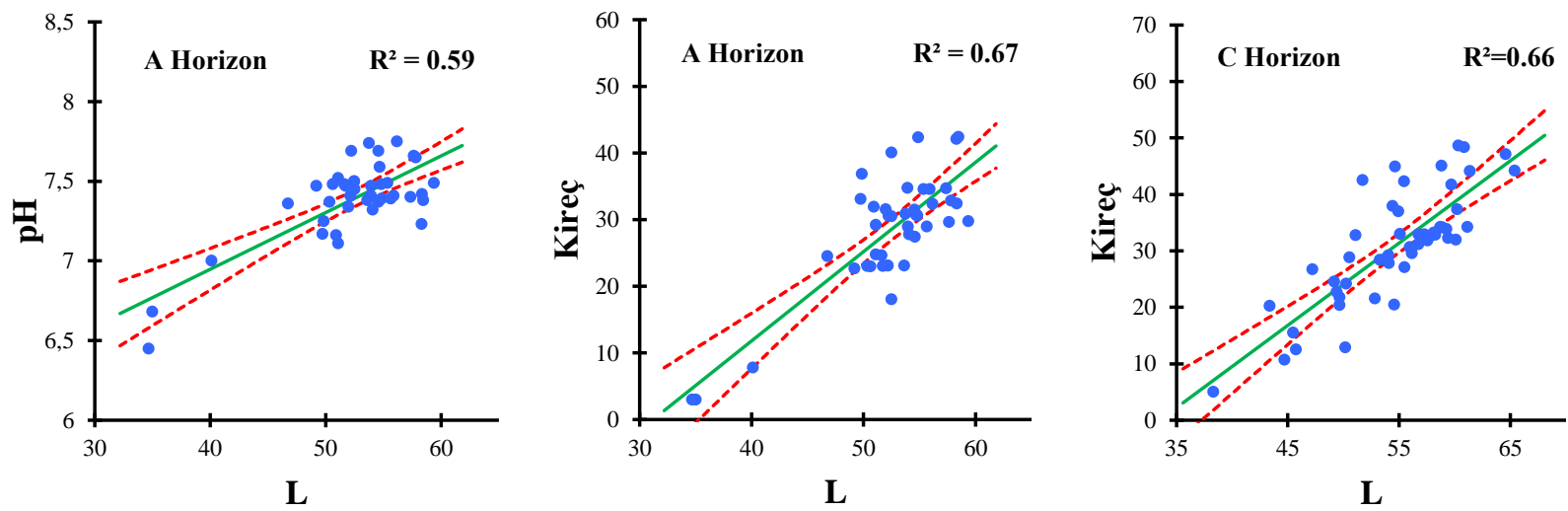

Şekil 5. Bazı toprak özellikleri ile L sayısal renk parametresi arasındaki regresyon grafikleri.

Figure 5. Regression graphs between some soil properties and $L$ digital color parameters.

Çizelge 3. Çoklu doğrusal regresyon (ÇDR) analizleri ile sayısal renk parametreleri ile toprak özelliklerinin tespit edilebilirliği.

Table 3. Determination of soil properties with digital color parameters with multiple linear regression (MLR) analysis.

\begin{tabular}{|c|c|c|c|c|c|c|}
\hline \multirow{2}{*}{$\begin{array}{l}\text { Toprak } \\
\text { Özellikleri }\end{array}$} & \multicolumn{3}{|c|}{ A Horizonu } & \multicolumn{3}{|c|}{ C Horizonu } \\
\hline & $\mathbf{R}^{2}$ & RMSE & ÇDR Modeli & $\overline{\mathbf{R}^{2}}$ & RMSE & ÇDR Modeli \\
\hline Kum & 0.27 & 14.60 & Kum $=(3.3 * b)-23.87$ & 0.41 & 17.36 & Kum $=-(2.78 * \mathrm{~L})-(4.91 * b)+100.88$ \\
\hline Silt & 0.19 & 9.33 & $\operatorname{Tin}=-(3.45 * a)+(1.80 * b)+36.42$ & 0.33 & 12.20 & $\operatorname{Tin}=-(1.51 * \mathrm{~L})-46.60$ \\
\hline Kil & 0.46 & 9.92 & $\mathrm{Kil}=-(3.40 * \mathrm{~b})+85.67$ & 0.41 & 13.20 & $\mathrm{Kil}=-(1.17 * \mathrm{~L})+(54 * \mathrm{~b})+45.18$ \\
\hline $\mathrm{pH}$ & 0.68 & 0.14 & $\mathrm{pH}=(0.03 * \mathrm{~L})-(0.05 * \mathrm{a})+6.28$ & 0.42 & 0.11 & $\mathrm{pH}=(0.02 * \mathrm{~L})+6.58$ \\
\hline EC & 0.02 & 0.02 & $\mathrm{EC}=(0.001 * \mathrm{~b})+0.001$ & 0.34 & 0.03 & $\mathrm{EC}=-(0.001 * \mathrm{a})+(0.01 * \mathrm{~b})-0.03$ \\
\hline Kireç & 0.73 & 4.71 & Kireç $=-(5.58 * a)+(3.67 * b)+13.17$ & 0.79 & 4.76 & Kireç $=(L * 0.72)-(2.55 * a)+(2.49 * b)-30.77$ \\
\hline OM & 0.07 & 0.73 & $\mathrm{OM}=-(0.11 * a)+2.97$ & 0.05 & 0.56 & $\mathrm{OM}=-(0.05 * \mathrm{~b})+2.16$ \\
\hline K & 0.27 & 0.36 & $\mathrm{~K}=-(0.09 * \mathrm{~L})-(0.28 * \mathrm{a})+(0.16 * \mathrm{~b})+5.08$ & 0.23 & 0.18 & $\mathrm{~K}=-(0.02 * \mathrm{~L})+1.53$ \\
\hline $\mathrm{Na}$ & 0.15 & 0.18 & $\mathrm{Na}=(\mathrm{L} * 0.01)-0.47$ & 0.28 & 0.40 & $\mathrm{Na}=-(0.19 * a)+(0.10 * b)+0.07$ \\
\hline $\mathrm{Ca}+\mathrm{Mg}$ & 0.49 & 6.43 & $\mathrm{Ca}+\mathrm{Mg}=(\mathrm{L} * 0.70)-(2.08 * b)+26.92$ & 0.11 & 7.26 & $\mathrm{Ca}+\mathrm{Mg}=-(0.90 * \mathrm{~b})+48.64$ \\
\hline KDK & 0.48 & 6.50 & $\mathrm{KDK}=(\mathrm{L} * 0.69)-(2.09 * \mathrm{~b})+28.83$ & 0.11 & 7.26 & $\mathrm{KDK}=-(0.89 * \mathrm{~b})+49.46$ \\
\hline
\end{tabular}




\section{Sonuç}

Morfometrik genetik olarak ölçülebilen ve toprağın birçok özelliği ile ilişkili olan renk özelliği, teknolojinin geliştiği çağımızda göreceli olmaktan ziyade, kesin bulgular ile ölçülmek istenmekte ve bu kıymetli özelliğin toprak oluşumundan, kullanımına kadar birçok bilimsel alana 1 şı tutması beklenmektedir. $\mathrm{Bu}$ konuda yapılan çalışmalara katkı sağlayarak, yeni bir bakış açısı ile tarımsal potansiyeli yüksek olan Aksu çayı aluviyal topraklarında gerçekleştirilen bu çalışmada, başka çalışmalara ek olarak renk özelliğinin, farklı bir yöntem ile ölçülmesi ve horizon farklılıkları bazında değerlendirilmesi hedeflenmiştir. Araştırma sonuçlarına göre toprağın A horizonlarında $\mathrm{L}$ değeri (Parlaklık) ile $\mathrm{pH}$ ve kireç arasında, a değeri (yeşil/kırmızı) ile kum, $\mathrm{pH}, \mathrm{Ca}+\mathrm{Mg}$ ve $\mathrm{KDK}$ arasında ve b değeri (sarı/mavi) ile kum, kil, $\mathrm{Ca}+\mathrm{Mg}$ ve $\mathrm{KDK}$ arasında önemli korelasyon olduğu tespit edilmiştir. Toprağın $\mathrm{C}$ horizonlarında ise $\mathrm{L}$ değeri ile silt, $\mathrm{pH}$, kireç ve $\mathrm{K}$ arasında, a değeri ile kil ve kireç arasında ve $\mathrm{b}$ değeri ile kil, kireç, $\mathrm{Ca}+\mathrm{Mg}$ ve KDK arasında önemli korelasyon olduğu tespit edilmiştir. Çoklu doğrusal regresyon analiz sonuçlarına göre; $\mathrm{A}$ horizonlarında $\mathrm{pH}$ değerinin $\mathrm{L}$ ve a değerleri ile ve kireç içeriğinin a ve b değerleri kullanılarak, $\mathrm{C}$ horizonlarında ise kireç içeriğinin $\mathrm{L}$, a ve $\mathrm{b}$ değerleri kullanılarak normal regresyon analizine göre daha yüksek doğrulukla, güvenilir, hızlı ve çevreye zarar vermeden ekonomik bir şekilde tespit edilebileceği belirlenmiştir. Aynı zamanda, sayısal renk parametrelerinin ( $\mathrm{L}$, a ve b) özellikle $\mathrm{pH}$ ve kireç içeriğinin belirlenmesinde güvenilir bir şekilde kullanılabilirliği üzerinde horizon farklılığından bir başka deyişle $\mathrm{A}$ ve $\mathrm{C}$ etkilendiği belirlenmiştir. Sonuç olarak toprak özelliklerinin sayısal renk parametreleri ile arasındaki ilişki ve aynı zamanda sayısal renk parametreleri ile tahmin edilme olasılığ arasındaki horizon farklılı̆̆ına bağlı heterojenliğin azaltılarak ilişkinin ve tahmin performansının artırılacağı öngörülmektedir.

\section{Kaynaklar}

Aitkenhead MJ, Coull M, Towers W, Hudson G, Black HIJ (2013) Prediction of soil characteristics and colour using data from the National Soils Inventory of Scotland. Geoderma 200: 99-107.

Barret LR (2002) Spectrophotometric color measurement in situ in well drained sandy soils. Geoderma 108: 49-77.

Baumann K, Schöning I, Schrumpf M, Ellerbrock RH, Leinweber P (2016) Rapid assessment of soil organic matter: Soil color analysis and Fourier transform infrared spectroscopy. Geoderma 278: 49-57.

Black CA (1965) Methods of Soil Analysis Part 2, Amer. Society of Agronomy Inc., Publisher Madisson, Wisconsin, U.S.A., 13721376.

Bouyoucos GJ (1955) A recalibration of the hydrometer method for making mechanical analysis of the soils. Agronomy Journal 4(9): 434.

Budak M, Gunal H (2016) Visible and near infrared spectroscopy techniques for determination of some physical and chemical properties in Kazova watershed. Advances in Environmental Biology 10(5): 61-73.

Budak M, Günal H, Süer M, Akbaş F (2018) Sayısal renk parametrelerinden bazı fiziksel ve kimyasal toprak özelliklerinin belirlenmesi. Harran Tarım ve Gıda Bilimleri Dergisi 22(3): 376389 .

Fan Z, Herrick JE, Saltzman R, Matteis C, Yudina A, Nocella N, Crawford E, Parker R, Van Zee J (2017) Measurement of Soil Color: A Comparison Between Smartphone Camera and the Munsell Color Charts. Soil Science Society of America Journal 81(5): 1139-1146.
Fang XM, Ono Y, Fukusawa H, Pan BT, Li JJ, Guan DH, Oi K, Tsukamoto S, Torii M, Mishima T (1999) Asian summer monsoon instability during the past 60.000 years: magnetic susceptibility and pedogenic evidence from the western Chinese Loess Plateau. Earth and Planetary Science Letters 168: 219-232.

Gözükara G, Altunbaş S, Sarı M (2019) Mekansal değişimin alüviyal fanlar üzerinde oluşan toprakların özelliklerine etkisi. Mediterrenean Agricultural Sciences 32(3): 425-435.

Gözükara G, Altunbaş S, Sarı M (2020) Zamansal ve mekansal değișimlerin eski göl tabanlarındaki toprak oluşumu, gelișimi ve morfolojisi üzerine etkisi. Harran Tarım ve Gıda Bilimleri Dergisi 24(1): 96-110.

Gozukara G, Zhang Y, Hartemink AE (2021) Using vis-NIR and pXRF data to distinguish soil parent materials - an example using 136 pedons from Wisconsin, USA. Geoderma 396: 115091.

Günal H, Erşahin S, Yetgin B, Kutlu B (2008) Use of chroma-meter measured color parameters in estimating color related soil variables. Communications in Soil Science and Plant Analysis 39(6): 726-740.

Hartemink AE, Minasny B (2014) Towards digital soil morphometrics. Geoderma 230-231.

Jackson MC (1967) Soil chemical analysis. Prentice Hall of India Private'Limited. New Delhi.

Ji JF, Chen J, Balsam W, Liu LW (2007) Quantitative analysis of hematite and goethite in the Chinese loess-paleosol sequences and its implication for dry and humid variability. Quaternary Sciences 27: 221-229.

Kacar B (1995) Bitki ve toprağın kimyasal analizler: III. Toprak Analizleri. A. Ü. Ziraat Fakültesi Geliştirme Vakfı Yayınları No: 3.

Lê S, Josse J, Husson F (2008) FactoMineR: An R Package for Multivariate Analysis. Journal of Statistical Software 25(1): 1-18.

Moritsuka N, Matsuoka K, Katsura K, Sano S, Yanai J (2014) Soil color analysis for statistically estimating total carbon. Total nitrogen and active iron contents in Japanese agricultural soils. Soil Science and Plant Nutrition 60(4): 475-485.

Post DF, Levine SJ, Bryant RB, Mays MD, Batchily AK, Escadafal R, Huete AR (1993) Correlations between field and laboratory measurements of soil color. In: Bigham. J.M.. Ciolkosz. E.J. (Eds.). Soil Color. Soil Science Society of America, Madison, WI., pp. 3550

Pretorius ML, Van Huyssteen C, Brown LR (2017) Soil color indicates carbon and wetlands: developing a color-proxy for soil organic carbon and wetland boundaries on sandy coastal plains in South Africa. Environmental Monitoring and Assessment 189(11): 556.

Rice TD, Nickerson D, O'Neal AM Thorp J (1941) Preliminary colorstandards and color names for soil. Miscellaneous Publication 425: 1-12.

Schulze DG, Nagel JL, Van Scoyoc GE, Henderson TL, Baumgardner MF, Stott DE (1993) Soil color. In: Bigham JM, Ciolkosz EJ (Eds), Significance of organic matter in determining soil colors. Soil Science Society of America Special Publications, Madison, pp. 7190 .

Shen ZX, Cao JJ, Zhang XY, Arimoto R, Ji JF, Balsam WL, Wang YQ, Zhang RJ, Li XX (2006) Spectroscopic analysis of iron-oxide minerals in aerosol particles from northern China. Science of the Total Environment 367: 899-907.

Simonson RW (1993) Soil color standards and terms for field use history of their development. In: In: Bigham. J.M.. Ciolkosz. E.J. (Eds.). Soil Color. SSSA Spec. Publ.. vol. 31. Soil Science Society of America. Madison. WI. pp. 1-20. doi: 10.2136/sssaspecpub31.

Soil Survey Staff (1993) Soil survey manual. Agricultural Handbook 18 Government Printing Office. Washington. DC

Soil Survey Staff (2010) Soil Taxonomy. 11th ed. USDA National Resources Conservation Services. Washington DC. 
Soil Survey Staff (2014) Keys to Soil Taxonomy. Twelfth Edition Edition, United States Department of Agriculture, Natural Resources Conservation Service ISBN 0-16-048848-6. Washington DC.

Şimşek O, Altunbaş S, Demirel BÇ, Gözükara G (2020) Alüviyal fizyografyalar üzerinde gelişen farklı topraklarda arazi değerlendirme çalışmaları. Mediterrenean Agricultural Sciences 33(1): $129-135$.

Thwaites R (2002) Color. In: Lal. R. (ed.) Encyclopedia of Soil Science. Marcel Dekkers. Inc., pp. 211-214.

Torrent J, Schwertmann U, Schulze DG (1980) Iron oxide mineralogy of some soils of two river terrace sequences in Spain. Geoderma 23: 191-208.
Torrent J, Barrón V (1993) Soil color. In: Bigham JM, Ciolkosz EJ (Eds), Laboratory measurement of soil color: Theory and practice. Soil Science Society of America Special Publications, Madison, pp. 21-33.

Vodyanitskii YN, Kirillova NP (2016) Application of the CIE-L* a* b* system to characterize soil color. Eurasian Soil Science 49(11): $1259-1268$

Zhang Y, Hartemink AE (2019) A method for automated soil horizon delineation using digital images. Geoderma 343: 97-115. 